\title{
PENILAIAN SAFETY INTEGRITY LEVEL IRADIATOR GAMMA KATEGORI-IV PADA KEGAGALAN SISTEM CRANE PENGONTROL SUMBER ZAT RADIOAKTIF
}

\author{
Niken Siwi Pamungkas, Rochim Bakti Cahyono ${ }^{2 *}$, Deni Swantomo
}

1) Magister Teknik Sistem, Fakultas Teknik, Universitas Gadjah Mada

J1. Teknika Utara No.3 Barek, D.I.Yogyakarta 55281

niken.011100291@gmail.com

2) Departemen Teknik Kimia, Fakultas Teknik, Universitas Gadjah Mada

Jl. Grafika No.2 Kampus UGM, D.I.Yogyakarta 55281

rochimbakti@ugm.ac.id

3) Teknokimia Nuklir, Sekolah Tinggi Teknologi Nuklir - Badan Tenaga Nuklir

Nasional

J1. Babarsari Kotak POB 6101/YKKB Sleman, D.I.Yogyakarta 55281

deni_sttn@yahoo.co.id

*Corresponding author

\begin{abstract}
ABSTRAK
PENILAIAN SAFETY INTEGRITY LEVEL IRADIATOR GAMMA KATEGORI-IV PADA KEGAGALAN SISTEM CRANE PENGONTROL SUMBER ZAT RADIOAKTIF. Penelitian penilaian Safety Integrity Level (SIL) telah dilakukan di fasilitas iradiasi kategori-IV pada sistem crane pengontrol pergerakan sumber zat radioaktif Cobalt-60. Tujuan dari penelitian ini adalah untuk menentukan tingkatan SIL pada iradiator gamma kategori-IV pada simulasi kegagalan sistem pergerakan crane sumber zat radioaktif. Safety integrity level merupakan cara untuk menunjukkan tingkat kegagalan yang masih dapat diterima dari fungsi keselamatan tertentu. Metode pendekatan yang digunakan pada penelitian ini adalah metode probabilistic risk assessment (PRA) dan independent protection layer (IPL). Nilai frekuensi risiko terhadap paparan sumber zat radioaktif Cobalt-60 saat instalasi iradiator gamma beroperasi adalah bernilai 1,7 x $10^{-2}$ fail/year. Nilai SIL dari simulasi kegagalan yang dilakukan adalah SIL-4 dengan nilai frekuensi kegagalan sebesar $7 \times 10^{-7}$ dengan mengoptimalkan sistem perlindungan high alarm dan interlock systems. Presentase pengurangan risiko yang didapatkan adalah sebesar $99,99 \%$.
\end{abstract}

Kata kunci:initial protection layer, iradiator gamma, probabilistic risk assessment, safety integrity level

\begin{abstract}
THE SAFETY INTEGRITY LEVEL ASSESSMENT OF CATEGORY-IV GAMMA IRRADIATOR IN RADIONUCLIDE SOURCE CONTROL CRANE SYSTEM FAILURE.The safety integrity level's study (SIL) has been conducted in a category-IV irradiation facility on Cobalt-60 radioactive source crane control system. The purpose of this study was to determine the level of SIL in the category-IV gamma irradiator at failure simulation on Cobalt-60 radioactive crane control system. The safety integrity level's is a way to show acceptable failure rates of certain safety functions. The approach methods that used in this research are Probabilistic Risk Assessment (PRA) and In Protection Layer (IPL). The risk frequency value for exposure the Cobalt-60 radioactive source at the installation of the gamma irradiator was $1,7 \times 10^{-2}$. The SIL value of the failure simulation performed is SIL-4 with a frequency value of $7 \times 10^{-7}$ with optimized high noise alarm and a interlock systems. The percentage of risk reduced is $99.99 \%$.
\end{abstract}

Keywords: gamma irradiator, initial protection layer, probabilistic risk assessment, safety integrity level 


\section{PENDAHULUAN}

Pertumbuhan jumlah penduduk di Indonesia sebanding dengan kebutuhan pasokan bahan pangan dan obat. Pasokan pangan dapat ditingkatkan dengan menekan kerugian akibat busuk atau rusak yang mencapai $60-70 \%$ karena kondisi tropis wilayah Indonesia yang lembab dan panas [5]. Proses pengawetan bahan makanan dan sterilisasi peralatan medis secara komersial dilakukan dengan penambahan bahan kimia dan pemberian panas yang mana kedua metode tersebut dapat diprediksi merusak secara bentuk, rasa, bau dan teksture. Oleh karena itu proses iradiasi ditawarkan sebagai salah satu pengawetan makanan [2,5].

Radiasi bahan pangan dan peralatan medis merupakan sebuah proses dimana bahan pangan dan alat medis dipaparkan radiasi gamma dari sumber radiasi. Tujuan dengan adanya pemaparan radiasi tersebut diharapkan mikroorganisme yang berpotensi dapat membuat busuk bahan pangan dan mengkontaminasi peralatan medis dapat dikurangi bahkan mati.

Peraturan Pemerintah No 33 Tahun 2007 tentang keselamatan radiasi pengion dan keamanan sumber radioaktif menjadi dasar pentingnya penilaian potensi risiko pada iradiator gamma. Analisis risiko potensi terjadinya ketidaknormalan dan kegagalan fungsi tersebut sehingga dapat dilakukan langkah penganggulangan sedini mungkin. Analisis risiko akan mempertimbangkan persyaratan dan peraturan keselamatan radiasi utama baik secara regional atau internasional. Pekerjaan yang melibatkan sumber radiasi sebelum dimulai harus dilakukan risk assessment. Metode risk assessment merupakan salah satu metode penilaian yang dikembangkan untuk mengetahui performa dari potensi paparan radiasi yang ditimbulkan dari kegiatan di fasilitas nuklir [8]. Hasil analisis risiko tersebut akan digunakan dalam pemberian rekomendasi atau kebijakan yang dapat dipertimbangkan dalam penyusunan dokumen proteksi radiasi iradiator gamma.Penilaian safety integrity level dilakukan untuk memastikan bahwa potensi risiko yang diprediksi timbul dapat dicegah dan diminimalisir [4].
Iradiator gamma serbaguna dikembangkan untuk iradiasi barang-barang dalam volume yang besar. Fasilitas ini digunakan untuk hasil-hasil pertanian, perkebunan, dan perikanan untuk meningkatkan waktu simpannya. Fasilitas ini juga digunakan untuk sterilisasi peralatan medis (seperti sarung tangan, jarum suntik, dan lain sebagainya) [10]. Iradiator pada kategori-IV dalam pilot-scale atau komersial menggunakan beberapa sumber radioaktif Co-60 berbentuk pinsil yang disusun dalam rak yang dapat berpindah dalam ruangan radiasi yang cukup besar. Ketika proses radiasi tidak berlangsung didalam ruangan, sumber radioaktif dilindungi dengan air (wet storage), timbal, atau bahan dengan nomor atom besar (dry storage).

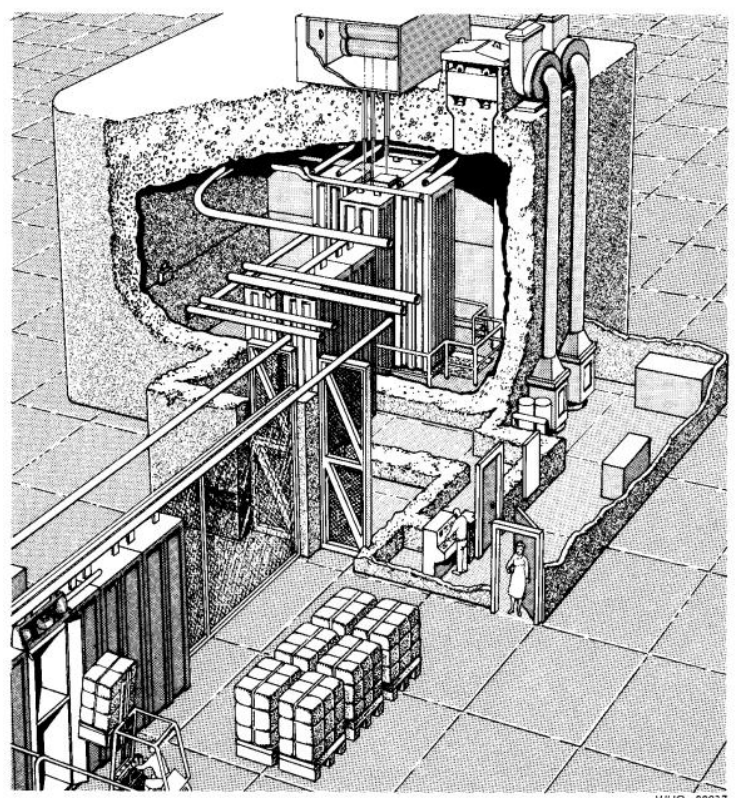

Gambar 1. Instalasi Iradiator Kategori-IV [5]

\section{Analisis Risiko}

Analisis risiko dapat didefinisikan dalam berbagai cara dan banyak definisi tergantung pada bagaimana analisis risiko berkaitan dengan konsep-konsep lain. Analisis risiko dapat didefinisikan secara luas mencakup penilaian risiko, karakterisasi risiko, komunikasi risiko, manajemen risiko, dan kebijakan yang berkaitan dengan risiko, dalam konteks risiko perhatian kepada individu, untuk publik dan organisasi sektor swasta, dan masyarakat pada regional, nasional, maupun tingkat global [15].

Pada dasarnya metode yang digunakan pada analisa risiko itu ada 3, yaitu [9]:

a. metode kualitatif 
b. metode kuantitatif

c. metode campuran (kualitatif dan kuantitatif)

\section{Safety Integrity Level (SIL)}

Setelah melakukan analisis potensi risiko dan mengkarakterisasinya kemudian dilakukan skenario untuk menentukan apakah perbaikan yang dilakukan terhadap risiko yang timbul akan memberikan indikator sebuah proses diharapkan berjalan dengan aman. Safety integrity level merupakan cara untuk menunjukkan tingkat kegagalan yang masih dapat diterima dari fungsi keselamatan tertentu. Pembagian tingkat analisis SIL disajikan pada Tabel 1 berikut ini.

\begin{tabular}{cccc}
\multicolumn{4}{c}{ Tabel 1. Tingkat Safety Integrity Level $[3,16]$} \\
\hline SIL & Availability & PFDavg & $\begin{array}{c}\text { Risk } \\
\text { Reduction }\end{array}$ \\
\hline 4 & $>99,99 \%$ & $10^{-5}$ to $10^{-4}$ & $10^{5}$ to $10^{4}$ \\
3 & $99,90 \%$ & $10^{-4}$ to $10^{-3}$ & $10^{4}$ to $10^{3}$ \\
2 & $99 \%-99,9 \%$ & $10^{-3}$ to $10^{-2}$ & $10^{3}$ to $10^{2}$ \\
1 & $90 \%-99 \%$ & $10^{-2}$ to $10^{-1}$ & $10^{2}$ to $10^{1}$ \\
\hline
\end{tabular}

\section{METODE}

Data yang digunakan dalam penelitian ini adalah component reliability data dari International Atomic Energy Agency (IAEA) [6] sebagai data sekunder serta data primer diperoleh dari desain atau layout iradiator gamma kategori-IV di Indonesia.

\section{Perhitungan Laju Paparan}

Perhitungan laju paparan sumber gamma Cobalt-60 diasumsikan berbentuk titik. Nilai laju paparan pada jarak $r$ meter dan sumber radiasi gamma berbentuk titik dengan aktivitas sebesar A curie mengikuti persamaan 1.

$$
\dot{\mathrm{X}}=\frac{\Gamma \cdot \mathrm{A}}{\mathrm{r}^{2}}
$$

Dengan $\dot{X}$ adalah laju paparan (R/jam); $\Gamma$ adalah faktor gamma (R.m²/Ci.jam); A adalah aktivitas (Ci) dan $r$ adalah jarak (m).
Analisis yang dilakukan diawal adalah menidentifikasi risiko kegagalan sensor kekencangan dicranepengangkatsumber ZRA gamma. Instalasi tersebut terletak didalam ruang utama instalasi iradiator yakni ruang iradiasi. Dampak yang akan ditimbulkan dari kegagalan sistem tersebut adalah paparan radiasi dengan waktu yang cukup lama atau lebih besar dari waktu operasi dari iradiator gamma. Paparan radiasi tersebut dapat menyebabkan bahaya terhadap pekerja dan lingkungan disekitar instalasi. Bahaya tersebut apabila terkena pada manusia akan berdampak kemandulan, rusaknya organ, atau kematian. Probabilitas dari kegagalan tersebut diprediksi dalam kategori akan sering terjadi karena instalasi iradiator akan berjalan selama 24 jam.

Nilai batas dosis (NBD) diatur dalam Peraturan Kepala BAPETEN (Badan Pengawas Tenaga Nuklir) Nomor 4 Tahun 2013 dosis efektif untuk pekerja radiasi adalah sebesar 20 $\mathrm{mSv}$ (milisievert)/tahun. Asumsi apabila 1 tahun jumlah jam kerja adalah 24 jam dalam 280 hari sehingga dosis efektif untuk pekerja radiasi menjadi $3 \mu \mathrm{Sv} / \mathrm{jam}$. Dosis efektif untuk masyarakat adalah sebesar $1 \mathrm{mSv} / \mathrm{jam}$. Asumsi jumlah jam kerja yang sama sehingga dosis efektif untuk masyarakat menjadi $0,1 \mu \mathrm{Sv} / \mathrm{jam}$.

Berdasarkan perhitungan(exposure rate)laju paparan radiasi ZRA gamma dengan menggunakan persamaan (1) pada instalasi iradiator pada jarak 1 meter dari sumber ZRA yang berupa titik bernilai 4064,58 Gy/jam. Laju paparan tersebut kemudian diubah menjadi laju dosis ekivalen dengan mengalikan dengan faktor bobot radiasi gamma sebersar 1,0(ICRP No.60 Tahun 1990) sehingga menjadi 4064,58 Sv/jam. Oleh karena mengacu pada Risk Curve Criterion for the Publicdari Dvorzhak et al (2016), exposure rate menggunakan parameter laju efektif. Laju ekivalen dari perhitungan sebelumnya diubah menjadi laju dosis efektif dengan mengalikan faktor bobot organ gonad sebesar 0,2 (ICRP No.60 Tahun 1990) sehingga menjadi 842,4 Sv/jam.Nilai dosis efektif tersebut merupakan nilai dengan faktor bobot jaringan atau organ terbesar yakni organ gonad (kelenjar kelamin). Oleh karena itu exposure rate didapatkan nilai 842,4 Sv/jam.

\section{HASIL DAN PEMBAHASAN}




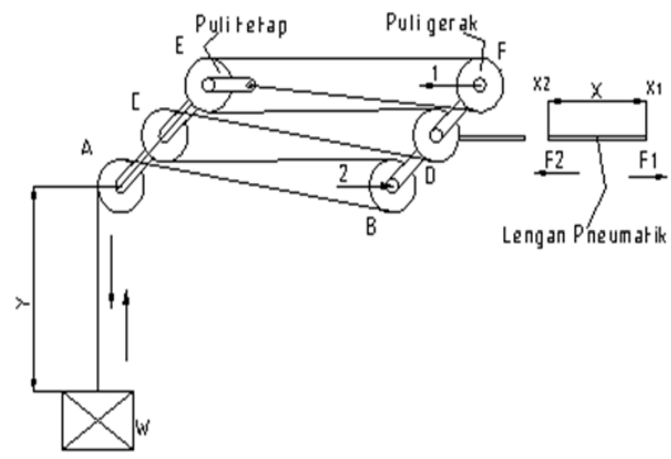

Gambar 2. Sistem Crane Sumber ZRA [11]

Kegagalan sistem terindikasi (iradiator gamma beroperasi) apabila sistem pneumatik untuk memutar puli gagal beroperasi menurunkan sumber ke dasar air pelindung. Satmoko et al (2015) menjelaskan pengembangan sistem perlindungan terhadap

potensi risiko gagalnya sistem naik dan turun sumber ZRA dapat dilakukan dengan pemasangan beberapa sensor magnetik, elektronik, dan kekencangan dimana semua akan terhubung pada sebuah pemrograman komputer.

Nilai perhitungan kemungkinan skenario dari kejadian kegagalan sistem crane adalah sebesar $1,7 \times 10^{-2}$ fail/tahun.Nilai tersebut masih dalam kategori berbahaya dan masih dibutuhkan lagi tindakan penanggulangan dan pencegahan. Penambahan instrumen penanggulangan, pencegahan, dan pengurangan nilai frekuensi akan dipertimbangkan berdasarkan tingkat risiko yang dimungkinkan terjadi (Tabel 2).Berdasarkan jumlah laju paparan sumber ZRA Cobalt-60 maka kasus ini masuk ke dalam "non acceptable" sehingga perlu dilakukan analisis proteksinya (Gambar $3)$.

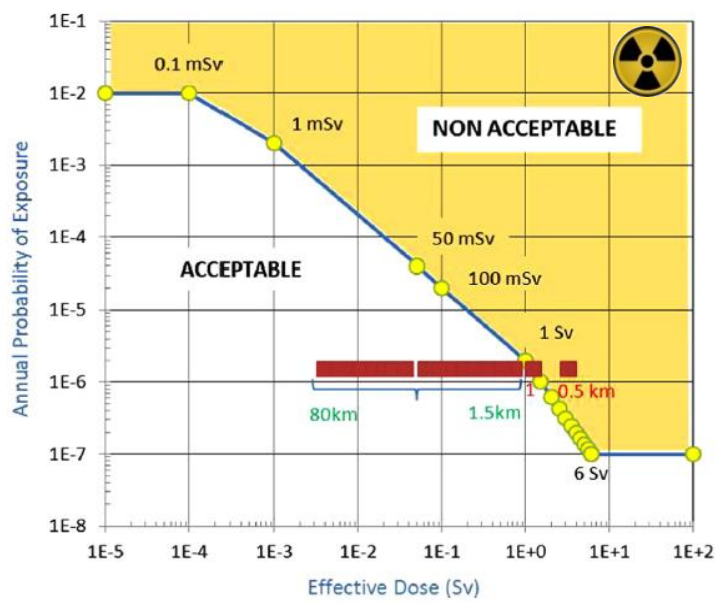

Gambar 3. Risk Curve Criterion for the Public [3]

Tabel 2. Consequence Severity Control

\begin{tabular}{|c|c|c|c|c|c|}
\hline \multirow{2}{*}{$\begin{array}{l}\text { Frequency of } \\
\text { Consequence } \\
\text { (per year) }\end{array}$} & \multicolumn{5}{|c|}{ Consequence Severity Category } \\
\hline & Category 1 & Category 2 & Category 3 & Category 4 & Category 5 \\
\hline $10^{-1}-1$ & $\begin{array}{l}\text { tolerable if ALARP - } \\
\text { evaluate alternatives }\end{array}$ & $\begin{array}{l}\text { tolerable if ALARP - } \\
\text { evaluate alternatives }\end{array}$ & $\begin{array}{l}\text { NOT TOLERABLE - } \\
\text { ACTION AT NEXT } \\
\text { OPPORTUNITY }\end{array}$ & $\begin{array}{l}\text { NOT TOLERABLE - } \\
\text { ACTION AT NEXT } \\
\text { OPPORTUNITY }\end{array}$ & $\begin{array}{l}\text { NOT TOLERABLE - } \\
\text { ACTION AT NEXT } \\
\text { OPPORTUNITY }\end{array}$ \\
\hline $10^{-2}-10^{-1}$ & $\begin{array}{l}\text { tolerable if ALARP - } \\
\text { evaluate alternatives }\end{array}$ & $\begin{array}{l}\text { tolerable if ALARP - } \\
\text { evaluate alternatives }\end{array}$ & $\begin{array}{l}\text { tolerable if ALARP - } \\
\text { evaluate alternatives }\end{array}$ & $\begin{array}{l}\text { NOT TOLERABLE - } \\
\text { ACTION AT NEXT } \\
\text { OPPORTUNITY } \\
\end{array}$ & $\begin{array}{l}\text { NOT TOLERABLE - } \\
\text { ACTION AT NEXT } \\
\text { OPPORTUNITY }\end{array}$ \\
\hline $10^{-3}-10^{-2}$ & $\begin{array}{l}\text { tolerable - no action } \\
\text { required }\end{array}$ & $\begin{array}{l}\text { tolerable if ALARP - } \\
\text { evaluate alternatives }\end{array}$ & $\begin{array}{l}\text { tolerable if ALARP - } \\
\text { evaluate alternatives }\end{array}$ & $\begin{array}{l}\text { NOT TOLERABLE - } \\
\text { ACTION AT NEXT } \\
\text { OPPORTUNITY }\end{array}$ & $\begin{array}{l}\text { NOT TOLERABLE - } \\
\text { ACTION AT NEXT } \\
\text { OPPORTUNITY } \\
\end{array}$ \\
\hline $10^{-4}-10^{-3}$ & $\begin{array}{l}\text { tolerable - no action } \\
\text { required }\end{array}$ & $\begin{array}{l}\text { tolerable - no action } \\
\text { required }\end{array}$ & $\begin{array}{l}\text { tolerable if ALARP - } \\
\text { evaluate alternatives }\end{array}$ & $\begin{array}{l}\text { tolerable if ALARP - } \\
\text { evaluate alternatives }\end{array}$ & $\begin{array}{l}\text { NOT TOLERABLE - } \\
\text { ACTION AT NEXT } \\
\text { OPPORTUNITY } \\
\end{array}$ \\
\hline $10^{-5}-10^{-4}$ & $\begin{array}{l}\text { tolerable - no action } \\
\text { required }\end{array}$ & $\begin{array}{l}\text { tolerable - no action } \\
\text { required }\end{array}$ & $\begin{array}{c}\text { tolerable - no action } \\
\text { required }\end{array}$ & $\begin{array}{l}\text { tolerable if ALARP - } \\
\text { evaluate alternatives }\end{array}$ & $\begin{array}{l}\text { tolerable if ALARP - } \\
\text { evaluate alternatives }\end{array}$ \\
\hline $10^{-6}-10^{-5}$ & $\begin{array}{c}\text { tolerable - no action } \\
\text { required }\end{array}$ & $\begin{array}{l}\text { tolerable - no action } \\
\text { required }\end{array}$ & $\begin{array}{c}\text { tolerable - no action } \\
\text { required }\end{array}$ & $\begin{array}{c}\text { tolerable - no action } \\
\text { required }\end{array}$ & $\begin{array}{l}\text { tolerable if ALARP - } \\
\text { evaluate alternatives }\end{array}$ \\
\hline $10^{-7}-10^{-6}$ & $\begin{array}{c}\text { tolerable - no action } \\
\text { required }\end{array}$ & $\begin{array}{c}\text { tolerable - no action } \\
\text { required }\end{array}$ & $\begin{array}{c}\text { tolerable - no action } \\
\text { required }\end{array}$ & $\begin{array}{c}\text { tolerable }- \text { no action } \\
\text { required }\end{array}$ & $\begin{array}{l}\text { tolerable - no action } \\
\text { required }\end{array}$ \\
\hline
\end{tabular}




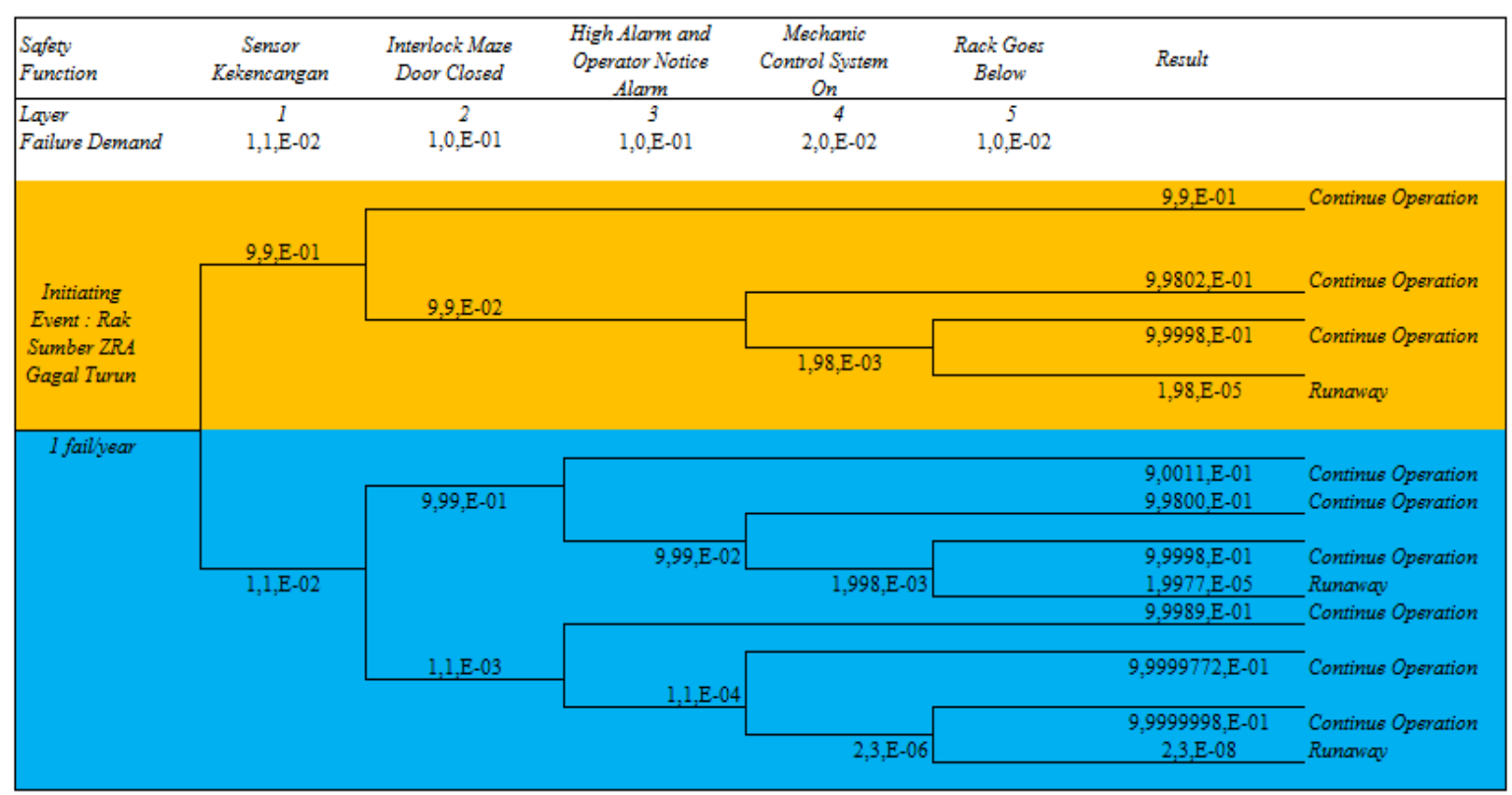

Gambar 4. Hasil Perhitungan IPL Pada Risiko Kegagalan Sensor Kekencangan

Risiko yang dianalisis adalah sistem crane failpengangkat sumber ZRA yang tidak dapat berjalan dengan baik pada saat menurunkan sumber ZRA. Analisis selanjutnya adalah perhitungan SIL dengan menggunakan IPL dengan mempertimbangkan pemasangan alat penanggulangan dan pelindungan. Risiko terjadinya kegagalan pada sistem crane sumber ZRA untuk IPL dihitung dengan Event Tree Analysis (ETA) sejalan dengan penelitian oleh Solanki, et al (2012) yang digunakan untuk penilaian keamanan fasilitas iradiasi bahan pangan.

Perhitungan diasumsikan terjadi kegagalan pada sistem crane switch sebanyak 1 kali gagal dalam satu tahun operasi. Nilai failure demand didapatkan dari data frekuensi kegagalan pada data component reliability dari IAEA dan industri terkait. Hasil perhitungan menggunakan ETA (Gambar 4) menunjukkan nilai frekuensi tanpa menggunakan high alarm didapatkan nilai $1,98 \times 10^{-5} \mathrm{fail} / \mathrm{tah} u n$ dan tingkatan SIL berdasarkan frekuensi pengurangan risiko tersebut yang hanya ada detektor radiasi adalah SIL-4. Target SIL yang harus dicapai pada sistem keamanan instalasi nuklir yakni SIL tingkat 4 [14]. Berdasarkan Tabel 2, nilai frekuensi tersebut masih dalam kategori risiko yang perlu ditangani lebih lanjut. Oleh karena itu, nilai frekuensi (probabilitas) terjadinya risiko dapat diturunkan dengan memberikan rekomendasi penambahan alat pendeteksi dini risiko. Nilai dampak atau konsekuensi tidak dapat diturunkan karena berasal dari karakteristik bahan utama yang dipaparkan ke lingkungan.

Rekomendasi diberikan dengan menambah high alarm sehingga nilai frekuensi kejadian adalah 2,3 x10-8 fail/tahun. Nilai frekuensi atau kemungkinan kejadian risiko dapat dikurangi. Penambahan high alarm nilai SIL nya adalah SIL-4. Jadi penambahan sistem keamanan high alarm dapat meningkatkan nilai SIL dan menurunkan nilai frekuensi kejadian risiko dengan persentasepengurangan risiko sebesar 99,99\%.

Rekomendasi yang diberikan akan menjadi pertimbangan sebuah instansi atau perusahaan untuk meningkatkan sistem keamanan. Semakin tinggi tingkatan SIL semakin tinggi pula biaya yang harus dikeluarkan oleh perusahaan atau instansi untuk menyediakan instrumen keselamatan [1]. Penelitian selanjutnya dapat mengembangkan metode pendekatan yang digunakan untuk analisis data kualitatif dan kuantitatif risiko.

\section{KESIMPULAN}

Risiko kegagalan sistem crane pengontrol pergerakan sumber zat radioaktif pada instalasi iradiator gamma diprediksi akan terjadi saat pengoperasian. Nilai frekuensi risiko kegagalan sensor pada sistem crane didapatkan nilai 0,017 fail/year. Penambahan high alarm dapat menurunkan nilai frekuensi 
probabilitas risiko sehingga mendapatkan tingkat SIL-4 dengan persentase pengurangan risiko sebesar $99,99 \%$.

\section{DAFTAR PUSTAKA}

1. Arindya, R; Hermanto, R. Studi Keselamatan Pembangkit Listrik Tenaga Nuklir. Prosiding Seminar Nasional Pengembangan Energi Nuklir V . 2012.

2. Budihardjo, S., Atmoko, D. F., Ramja, S., Sutomo, Suntoro, A., Pudjijanto, M. S. Desain Konsep Rancang Bangun Iradiator Gamma (ISG-500) Untuk Pengawetan Hasil Pertanian. Pertemuan Ilmiah Rekayasa Perangkat Nuklir. Jakarta: PRFN.2010.

3. Dvorzhak, A., Mora, J., \& Robles, B. Probabilistic Risk Assessment from Potential Exposures to the Public Applied for Innovative Nuclear Installations. Reliability Engineering and System Safety - ELSEVIER, 176-186.2016.

4. Elisabeth, S.(8 Juli 2017). Available : http://sinarharapan.net/2017/02/iradiator -gama-merah-putih-launching-agustus2017/.

5. IAEA \& FAO. Fact About Food Radiation. 1999

6. IAEA. Component Reliability Data For Use In Probabilistic Safety Assessment. Austria: IAEA.1988.

7. Isamov, R. T., Derevyankin, A. A., Zhukov, I. V., Berberova, M. A., Glukbov, I. V., \& Islamov, D. R. Risk Assessment of Nuclear Power Plant. 109.2010.

8. Jeong, K., Lee, K., \& Lim, H. Risk Assessment on Hazards for Decommisioning Safety of a Nuclear Facility. Annals of Nuclear Energy Science Direct, 1751-1762.2010.

9. Molak, V. Fundamentals of Risk Analysis and Risk Management. Ohio: Lewis.1997.

10. PRFN.Penyiapan SDM Operator Iradiator Serbaguna Puspitek Serpong.2017.

11. Satmoko, A., \& Gunawan, H. A. Desain Mekanik dan Pengendalian Gerak Rak Sumber Isotop Pada Iradiator Gamma 200 kCi. Jurnal Perangkat Nuklir .2015.
12. Solanki, R., Prasad, M., Sonawane, A., \& Gupta, S.Probabilistic Safety Assessment for Food Irradiation Facility. Elsevier , 123-130.2012.

13. Thomson, J.Nuclear Power Station Control And Instrumentation Safety Systems Architecture - An Overview. www.safetyinengineering.com.2012.

14. Wardhana, W. Teknologi Nuklir Proteksi Radiasi dan Aplikasinya. Yogyakarta: Andi.2007.

15. Warwick, B. The Handbook of Risk. Canada: John Wiley and Sons.2003.

16. Yoo, H., Lee, N., Ham, T., \& Seo, J.Methodology for Analyzing Risk at Nuclear Facility. Annals of Nuclear Energy , 213-218. 2015. 